\title{
Research on the Human Settlement Environment of Post-Disaster Reconstruction Villages from the Perspective of Regional Culture-A Case Study of Dong Village in Baojing
}

\author{
Mengdi Bian \\ College of Urban Planning and Architecture, Southwest Minzu University, Chengdu, China \\ Email:1073657369@qq.com
}

How to cite this paper: Bian, M.D. (2020) Research on the Human Settlement Environment of Post-Disaster Reconstruction Villages from the Perspective of Regional Culture-A Case Study of Dong Village in Baojing. Open Access Library Journal, 7: e6764.

https://doi.org/10.4236/oalib.1106764

Received: September 1, 2020

Accepted: September 24, 2020

Published: September 27, 2020

Copyright $\odot 2020$ by author(s) and Open Access Library Inc.

This work is licensed under the Creative Commons Attribution International License (CC BY 4.0).

http://creativecommons.org/licenses/by/4.0/

\begin{abstract}
As the largest and most complete North Dong village in the southeast of Guizhou province, Baojing Dong Village has been included in the list of national traditional villages. A fire has destroyed the integrity and uniqueness of the Baojing Dong Village. The purpose of this paper is to sort out the status quo of the human settlement environment in Baojing Dong Village after reconstruction, observe whether there is a qualitative change due to reconstruction and think about it and put forward some suggestions. In this paper, from the historical origin, natural landscape, cultural landscape, residential buildings, infrastructure construction, production and living ways from six angles in-depth analysis of the reconstruction of Baojing Dong village status quo, the place where change compared with original style research, and through real-time interview directly understanding native villagers to rebuild villages of satisfaction and evaluation, to rebuild after the advantages and existing problems of thinking, puts forward some corresponding development suggestions, maximum limit retained at Baojing Dong village cultural features, helps to Baojing Dong village with the sustainable development in the future.
\end{abstract}

\section{Subject Areas}

Architecture

\section{Keywords}

Regional Culture, Dong Village in Baojing City, The Human Settlement Environment, Post-Disaster Reconstruction 


\section{Preface}

The protection and development of traditional villages are an important issue in China's rural development, which cannot be ignored. The construction of traditional villages is a unique natural condition, and the wisdom product of the ingenious combination of the ancient people's philosophy, life and production mode is also the product of local planning with the most Chinese characteristics (Miao Jianping, 2014) [1]. However, with the development of the society, traditional villages in China are suffering from serious damage, unique cultural connotation of traditional village also disappears, traditional villages have not been the elegant demeanour, it is very urgent to the research of the traditional village living environment. At the same time, the suitable living environment to promote economic system and natural ecological system coordinated development of human society is of great significance.

Traditional village is the product of with Chinese characteristics. The research on the human settlement environment of traditional villages is mainly concentrated in China, and domestic academic circles have also achieved good research results. For example, Professor Zhao Wanmin has made a detailed study on the human settlement environment in mountainous areas, urban human settlement environment and design, etc. (Zhao Wanmin, 2010) [2]. Mr. Liu Dunxie has made a relatively systematic analysis on the overall traditional residential buildings in China. Professor Chen Zhihua, Lou Qingxi and other professors from Tsinghua University have carried out a lot of surveying and mapping and research work on traditional ancient villages in China. However, in the literature review, it is found that there are few targeted studies on the current situation of social environment after the reconstruction of traditional villages after being destroyed. The occurrence of the disaster is irreversible, it is urgent to preserve the cultural characteristics of traditional villages to the maximum extent. Standing on the basis of previous studies, this paper selects Baojing Dong Village with both traditional village and reconstruction background as the research object, to study at Baojing Dong Village the human settlement environment of the status quo, advantages and existing problems on the reconstruction and puts forward suggestions and opinions. In order to correctly handle the relationship between the old and the new in the future construction of traditional villages, it can not only maintain the original regional characteristics and traditional features, but also improve the modern public infrastructure, effectively promote the sustainable development of villages.

\section{General Situation of Dong Village in Baojing}

Baojing Township is the largest Dong settlement in the north southeast of Guizhou province, it is called the First Village of North Dong, and belongs to Zhenyuan County, Qiandongnan Miao and Dong Autonomous Prefecture, Guizhou Province. In 2013, Baojing Dong Village was listed in the second batch of Traditional Chinese villages. The village still maintains the traditional way of 
production and life. And in 2014, "Baojing Sanyuesan" in Zhenyuan County, Guizhou Province was included in the fourth batch of national intangible cultural heritage projects.

Dong Village of Baojing is the seat of government of Baojing township, 39 kilometers away from the town far county, the whole township has jurisdiction over 6 village committees, including Pine and cypress, Stone bridge, Tunshang, Baojing, Newsphoto and Guisha. The town covers an area of 69 square kilometers and has a population of about 10,365 people. There are more than 470 households and 2000 dong people living in The Dong Village of Baojing, which has a history of more than 300 years.

\section{Analysis of the Elements of Human Settlement Environment}

\subsection{History and Culture}

It is said that during the Reign of Emperor Yongle of the Ming Dynasty, local gold was produced in Baojing and dong leaders submitted the gold to the Ming Court, hence the name of "Reporting gold". In 1950, the government changed "gold" to "Baojing", hence the name of "reporting Gold" Dong Village in Baojing.

According to the "Zhenyuan, a famous historical and cultural city in China" records, long, Zhou, Tai, Wu, Tian and other family names in the late Ming and early Qing dynasty, moved in from Tianzhu County, Li moved in from Jianhe County. There are 757 households and 2854 people in the village, all of which are Of dong nationality. The main names are Dragon, Zhou, Liu, Tian, Tai, Li and $\mathrm{Wu}$. In 1985, zhenyuan County people's government designated the village as the first national tourist customs point, open to the outside world. In 2013, Baojing Dong Village was selected into the first batch of "Chinese Traditional Villages" list.

Often in remote ethnic-minority areas, groups are based on surnames. The dong Village in Beijing is inhabited by hundreds of family names. The zhou, Long, Li and Tian of Baojing married each other, effectively avoiding the marriage of close relatives. Family names live in harmony for a long time, which is rare in rural areas, especially in remote areas ("Zhenyuan, a famous historical and cultural city in China”. Zhenyuan County Shi Zhi Office) [3].

On January 25, 2014, a fire broke out in The Dong Village in Baojing, burning down 470 rooms of 148 buildings and affecting 1084 people in 296 households. After the fire in January 2014, the Zhenyuan County Party Committee and the county government took the measures of "unified planning, unified arrangement and unified construction" in accordance with the principle of "repairing the old as the old" to restore the architectural style of Dong Village in Baojing. In 2015, disaster-affected people returned to Dong Village.

\subsection{Natural Scenery}

According to the Dong people, rolling mountains are called "dragon vein", the 
gentle place is called "Dragon's head", and the flat place where the river crosses in front of the dragon's head is called "Dragon's mouth". The best site for the Dong village is the flat place near the river, which is called "Sitting dragon's mouth". And according to geomantic theory, the place where the water passes is "Yin", the place where the mountain is "Yang", the place where the water surrounds the mountain can hide the wind to gather gas most, be helpful for people to live and reproduce.

Therefore, the Dong Village in Baojing is located in the valley zone among mountains and mountains, with gentle terrain, dense vegetation and intermingled water system. The village from north to south, from high to low, like a fork mouth. Residential buildings cleverly make use of the terrain, which spreads longitudinally along the mountain, with horizontal and vertical contour lines spreading, and houses with scales and density alternate. The villagers make full use of the low-lying areas to cultivate rice and the high mountains to plant fir forests, forming a landscape system of "green mountains above and terraced fields below" that integrates natural landscape and cultural landscape.

Overlooking the whole Dong Village, we can find that the architectural layout of the rebuilt Dong Village is like a running goat with horns, eyes, tail and legs, and different styles can be seen from different angles (Figure 1).

\subsection{Node of Cultural Landscape}

\subsubsection{The Baojing Drum Tower}

As the spiritual center of the traditional Dong Village, Drum Tower is located in the center of the village. It is also the tallest and largest building in dong Village and plays the role of leading the whole village. The bottom of the Baojing drum tower has a regular quadrilateral shape and is supported by 16 large, equidistant wooden pillars. There are nine layers of eaves in The Building. The dong ancestors

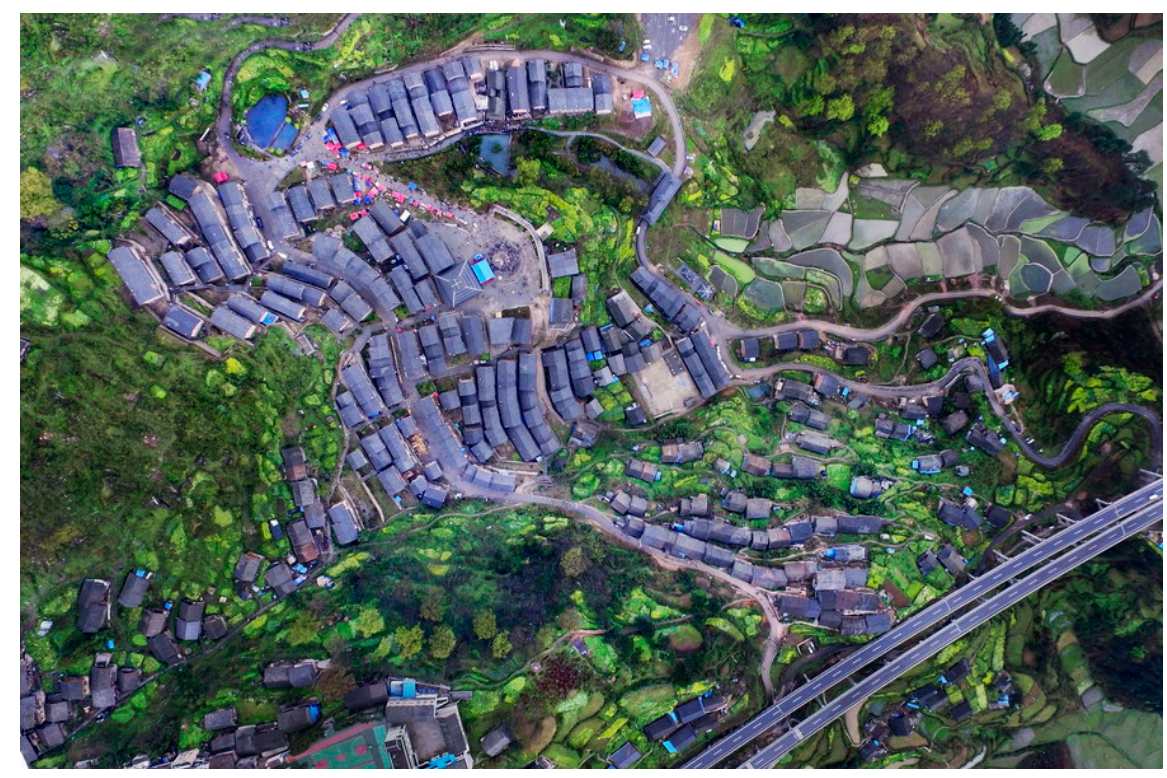

Figure 1. Aerial photo of Baojing Dong Zhai (Source network). 
believe that the odd number is Yang, representing the male, which means that people are thriving and prosperous. The cornice facade is shaped like an umbrella, with four flying curves on each floor. The curved end is called "hook", and it is decorated with simplified animal shape, which means good luck and health (Figure 2).

The square in front of The Baojing drum tower is the activity center of the villagers and the venue for large-scale activities, which was built after the disaster. Square ground with cobblestone paste into dong Village pattern, meaning auspicious. On the left side of the square is the service center for villagers, a three-story brick and concrete building (Figure 3 ). On the right are the newly built intangible cultural heritage exhibition hall and rural e-commerce poverty alleviation service station, which are two-story buildings of mixed brick and wood, retaining the traditional parts, such as the corridor and the beauty lounge (Figure 4). At the front of the square is a project supported by hangzhou's counterpart. A concrete and wood-like ethnic storm corridor, about 60 meters long and 2 meters wide, is built. Both sides of the square are lined with beauties to provide leisure and entertainment for villagers (Figure 5).
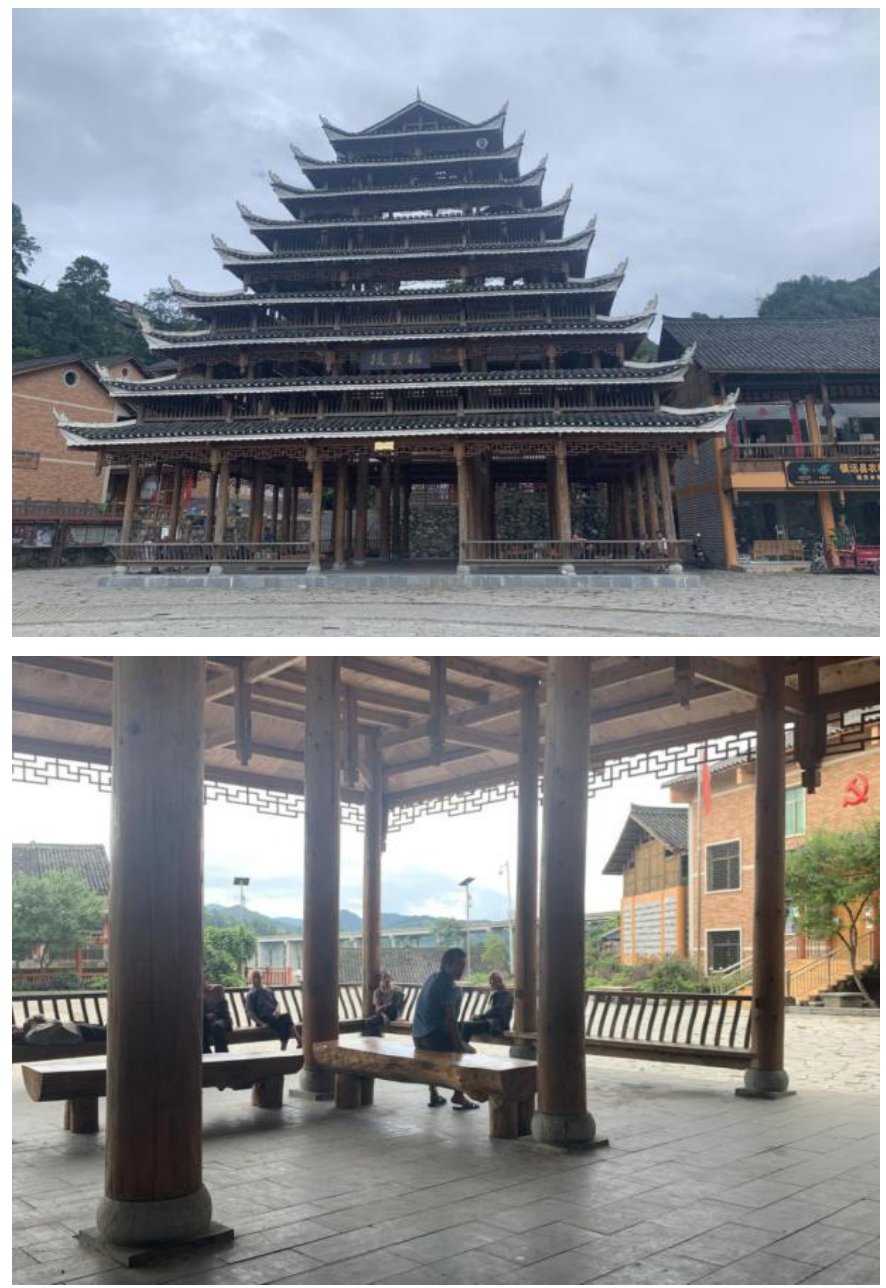

Figure 2. BaoJing drum tower (Photo by the author). 


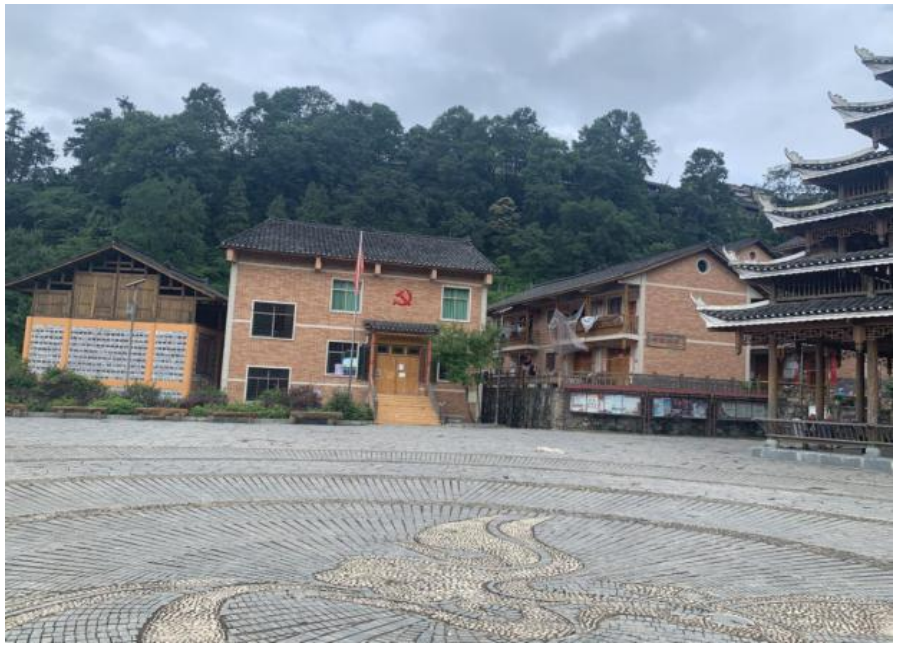

Figure 3. Village service center (Photo by the author).

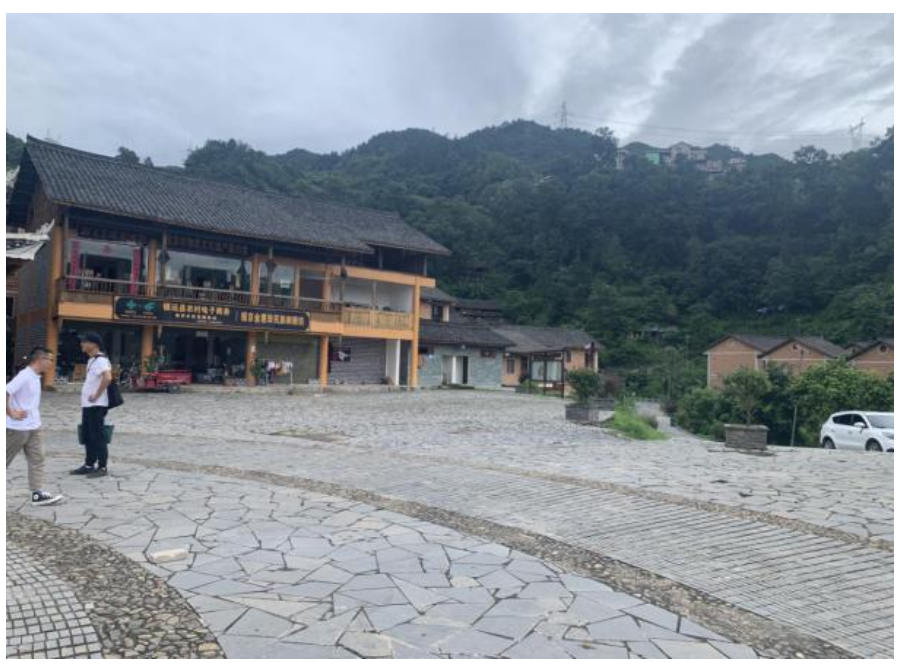

Figure 4. Intangible cultural heritage exhibition hall (Photo by the author).



Figure 5. Gallery of wind and rain (taken by the author). 


\subsubsection{Wind and Rain Bridge}

Water is the guarantee of the production and life style of the Dong people. In the eyes of the Dong people, water is the source of money for the whole village. If there is water, there is property. Dong people believe that drum tower and Wind and rain bridge can eliminate the misfortune and disaster of the village, block evil spirits, protect feng shui, and protect peace. The Dong people say that if the river flows from the entrance to the village and then flows out from the exit, the property will be lost. They build a wind and rain bridge over the river to intercept feng shui, retain the money of the village and improve people's living standard (Figure 6).

\subsubsection{Dong Village Gate}

As a part of "Drum Tower culture" of Dong Nationality, Village gate is the living embodiment of dong village's economic level and the guarantee of villagers' safety and health. The village gate is regarded by the Dong family as a place for guarding the village from diseases and disasters. At first, the village gate was used to defend against foreign invasion and prevent the flight of poultry and livestock (Yuan Wanqiu, 2018) [4]. Later, it gradually weakened its function and mainly played a beautifying role. The cedarwood with good plasticity and symbolic significance is selected as the building material, which reflects the ecological wisdom of adapting to nature in the traditional building construction of Dong people. Figure 7 is the newly built gate of Dong Village in Baojing. It is one of the landmark buildings of Dong Village with larger size and more exquisite shape. Figure 8 shows the renovated Laozhai Gate with a small span and a high elevation overlooking the whole village.

\subsubsection{The Moga Tree}

The Baojing Dong village, located in a valley between mountains and mountains, has a forest coverage rate of $56 \%$. There are 258 ancient trees over 100 years old,



Figure 6. Wind and rain bridge (Source network). 




Figure 7. New baojing village gate (Source network).

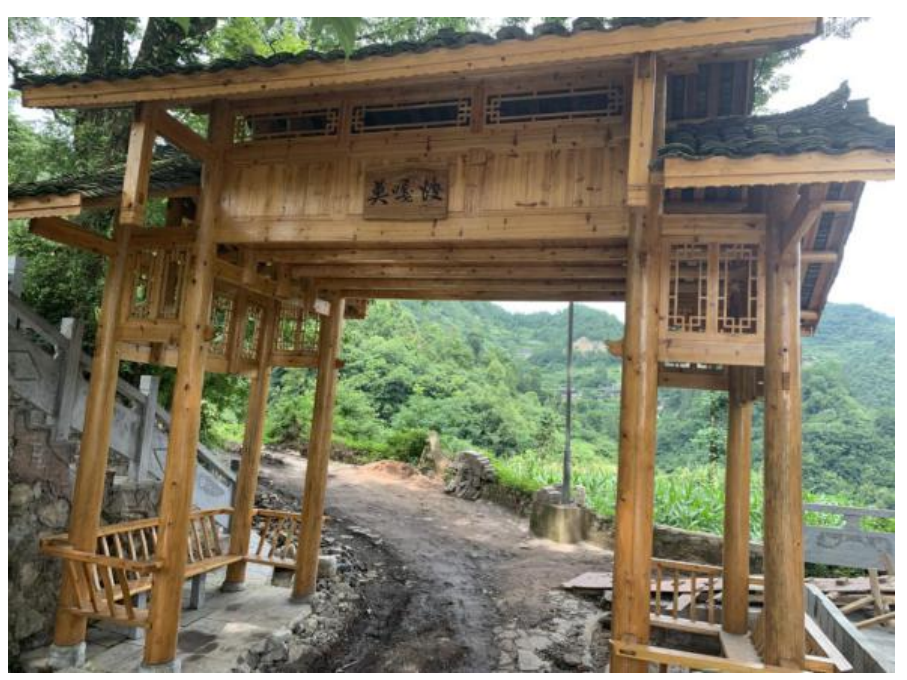

Figure 8. Old baojing village gate (taken by the author).

including 15 species such as beech, maple, ginkgo and Nanmu. Among them, the oldest and most historically valuable ancient tree is the King of beech tree: Moga Tree. According to research, it has a history of more than 1000 years. Among them, the oldest and most historically valuable ancient tree is the Beech king Moga tree, which has a history of more than 1000 years according to textual research. At the foot of the tree road, there is a stone tablet standing in the fourth year of the Reign of Emperor Xianfeng of the Qing Dynasty, inscribed with the words "Preserve an ancient tree for immortality in this generation". It is a sacred tree for the whole village to sacrifice. According to villagers, every year on the first day of the first lunar month, villagers sacrifice trees and stones. After offering sacrifices to the tree, they would also pick some leaves to take home to ensure geely's safety. On the third day of march every year, the girls in the village would carry a bamboo basket with shallots and garlic on it, and the boys, blowing the lusheng, would meet under the moga tree to sing love songs and tell each other the truth (Figure 9 and Figure 10). 


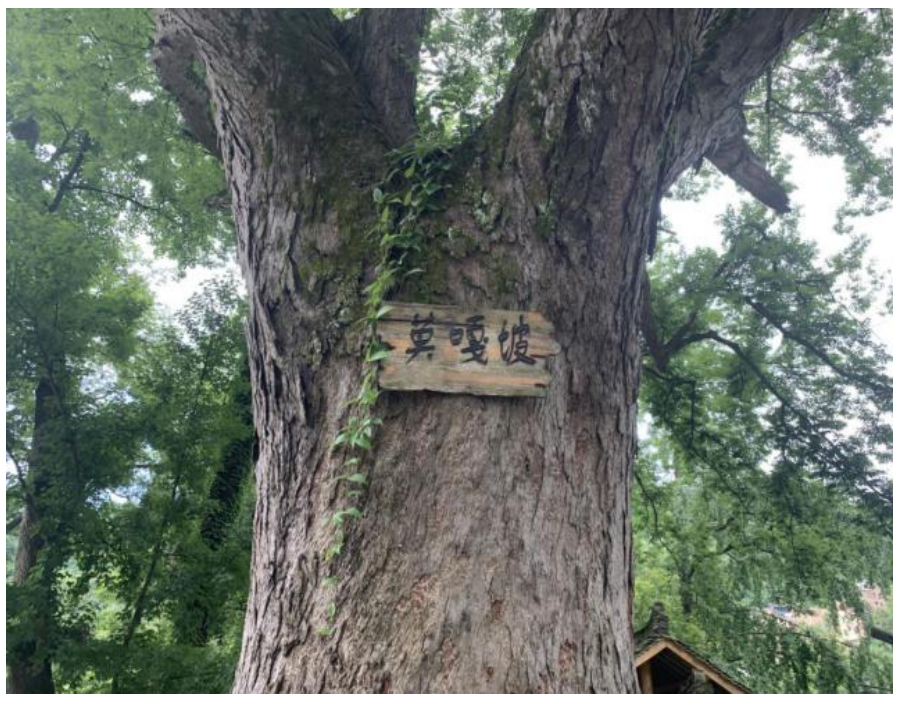

Figure 9. The mogga tree (self-shot by the author).

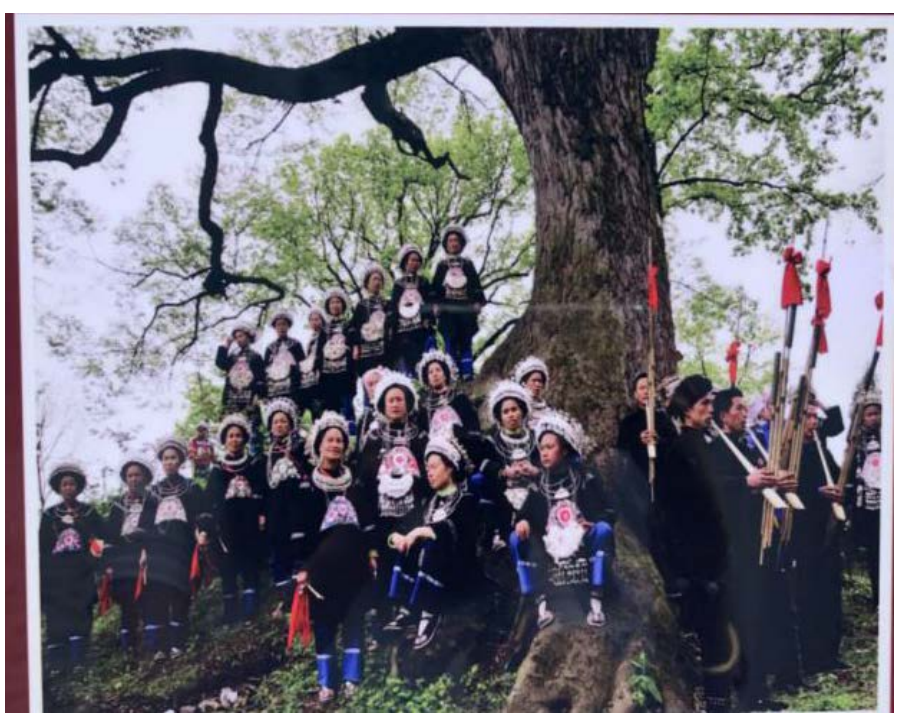

Figure 10. The opposite song under Mogga Slope (self-shot by the author).

\subsubsection{Beg Onion Pond}

The third day of March traditional festival is an intangible cultural heritage, also known as the "sowing Festival", commonly known as "begging onion garlic", hence the name of the spring Onion pond. Festival on this day, dressed in costumes of dong girls around for green pond in a row, on the bamboo basket, beg Onions in the pond wash onion (moral prosperous onion garlic in the dong people's eyes, people who), after wash, walk around the pond to the lover's bridge, waiting for the right guy came for onion, if after, the girl was put in the hands of green basket donative person, as two of a kind (Figure 11). Beg onion pond is an activity base for intangible cultural heritage. After the fire, the government carried out consolidation and upgrading construction, carried out regular desilting, and maintained greening (Figure 12). 


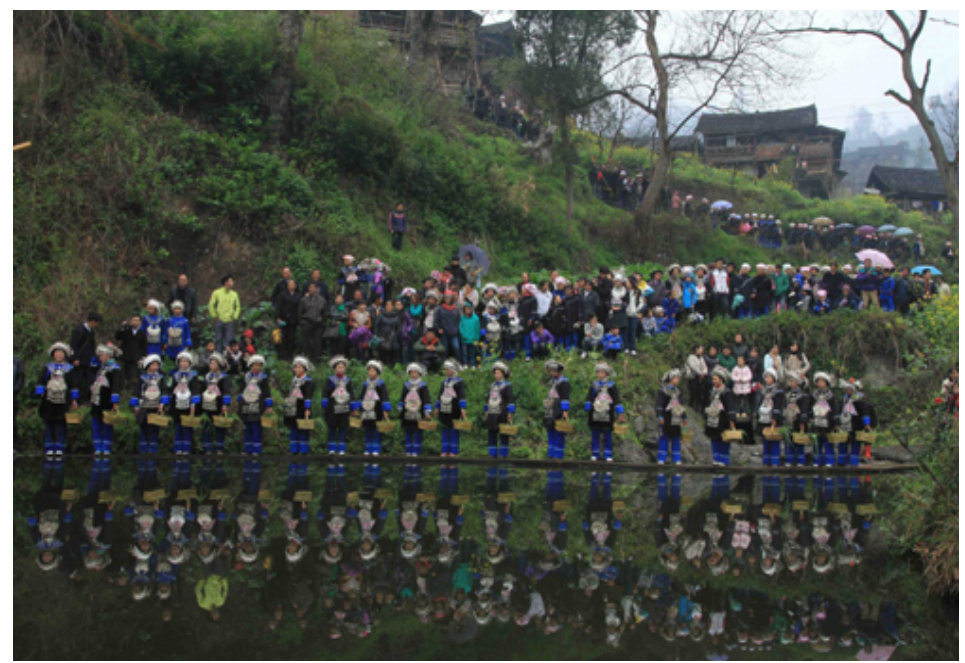

Figure 11. Beg onion pond (Source network).

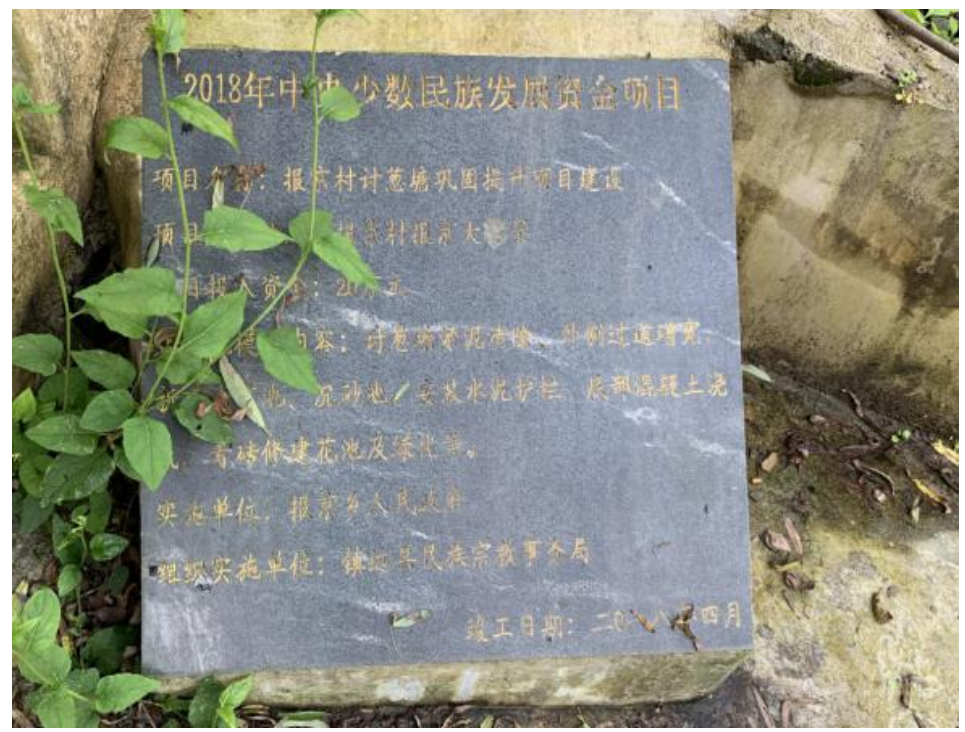

Figure 12. Consolidation project (taken by the author).

\subsubsection{The Ancient Well}

At the foot of Moga Slope, there is an ancient well with a long history. The inscription beside it records the history of the ancient well (built in the Qing Dynasty). The ancient well is almost responsible for the washing of the whole village. At the back, the spring water is channeled into the pool through the elevation drop, providing the villagers with the purpose of washing vegetables and washing clothes. The ancient well is warm in spring and cool in summer.

Before the reconstruction, the ancient well is in the form of a wooden pavilion, which ACTS as a shelter from the wind and rain. The green tiles, fir trees and beauty roots vividly show the charm of dong architecture Figure 13). The reconstructed pavilion is made of typical concrete, with a gray stone fence next to the ancient well and a large number of poplars and willows planted by the pond, just like a Chinese garden (Figure 14). 




Figure 13. Before reconstruction (self-shot by the author).

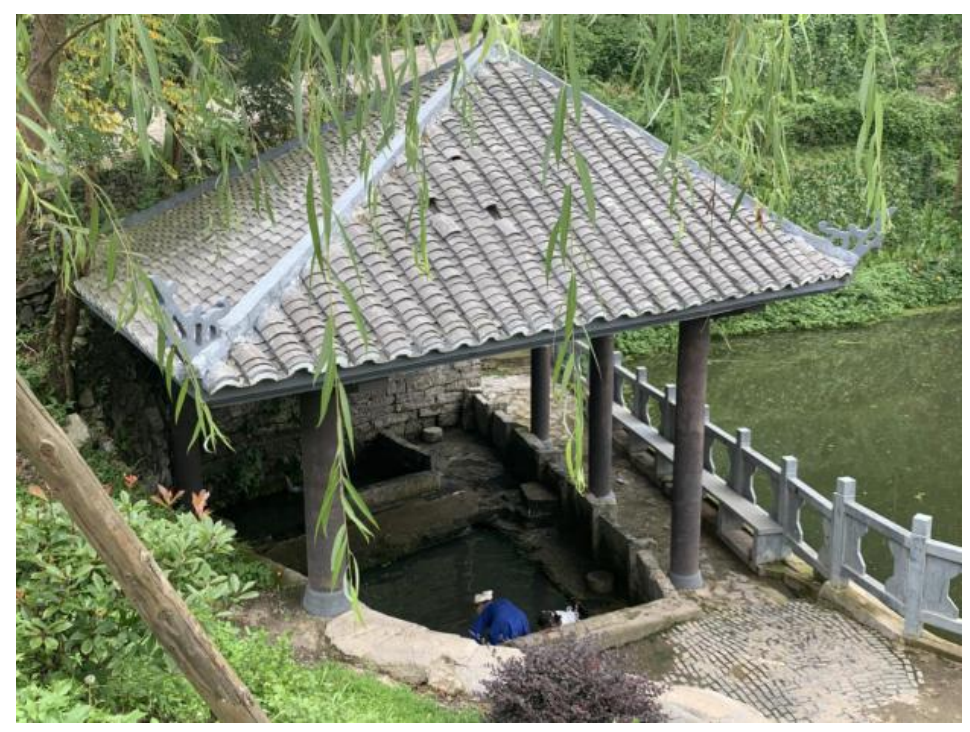

Figure 14. After reconstruction (self-shot by the author).

\subsection{Residential Architecture}

Before reconstruction, dongzhai folk houses in Baojing dong Village are unified traditional dry buildings, builted following the mountain. They are stacked on top of each other and scattered with a sense of rhythm of nature. They are the epitome of dong traditional buildings. Dong Village ganlan type wooden house, not only in the appearance of exquisite and clever, but also in the structure and mechanics of deep research. It is a perfect example of traditional Chinese architecture. In terms of the purpose of the northern Dong dwellings, the ancestors of the Dong ethnic group adopted the separation measures of "living on top of people and animals below", which not only effectively saved land and wood, but also prevented the theft of livestock, dampproof, summer heat, and snake and beast (Figure 15). 


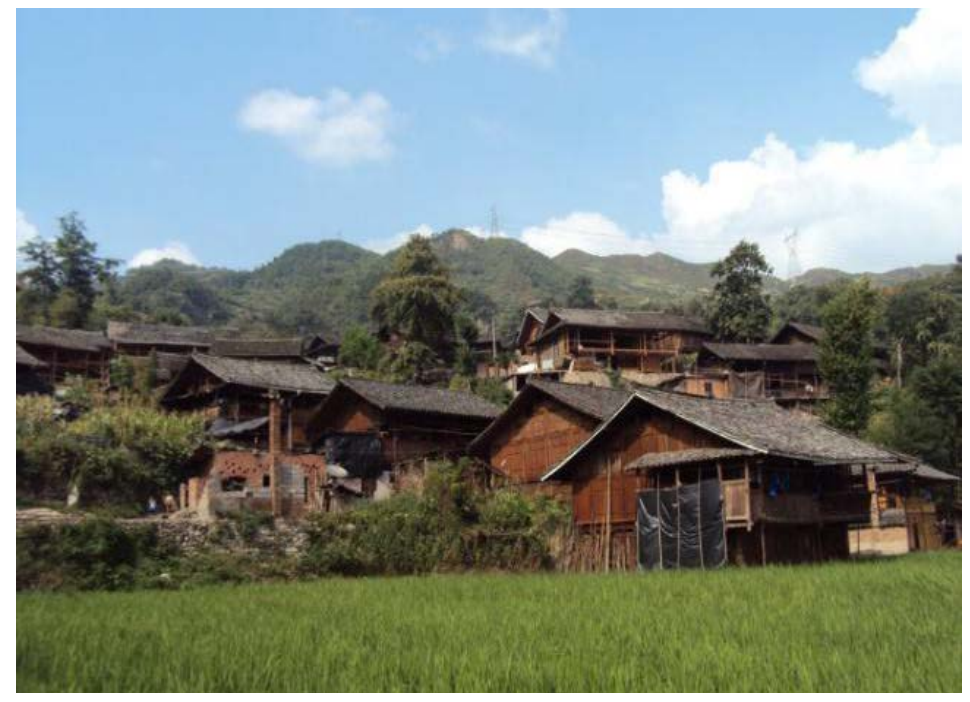

Figure 15. Before reconstruction (Source network).

In dong Village dwellings rebuilt after the disaster, unified construction specifications are adopted, limiting the height of the houses to no more than 3 stories and 12 meters, unifying the building appearance, centralized townhouses are built to separate the human and livestock, and the livestock enclosure of each family is centralized outside the residential area. All the newly-built dwellings in Dong Village are of the same architectural color of red brick and green excavation. The beautiful bench on the second floor and the carved frame in front of the house make the whole present the new rural dwelling pattern of the integration of national culture and modern style on the two floors. The dwelling houses are basically rebuilt on the original site and built along the mountain, and they are scattered among each other. At the same time, there is a certain distance between each adjacent building to prevent the recurrence of the disaster (Figure 16). The houses built along the street, the first floor is the hall or front hall, which is usually open with four doors, instead of the primitive wooden fence built for livestock. The doors are also decorated with some decorations, beautiful and anti-theft. The interior furnishings of the first floor adapt to modern life relatively, no longer retain the traditional fireplace space, but every family still retain the traditional ground pot, but also into the refrigerator, induction cooker, gas stove and other modern kitchen appliances, villagers have also got rid of the traditional way of life of cooking over a fire. The second floor is usually used as the living room and bedroom of a family. The top floor is generally used for piling up sundry things and storing food. This circular window hole is set on both sides of the building for ventilation and heat dissipation (Figure 17).

\subsection{Infrastructure Construction}

In the compilation of "The Post-disaster Reconstruction Plan of Baojing Township Baojing Village, Zhenyuan County, Guizhou Province”, it aims to build Baojing into a demonstration site for post-disaster reconstruction, rural housing 


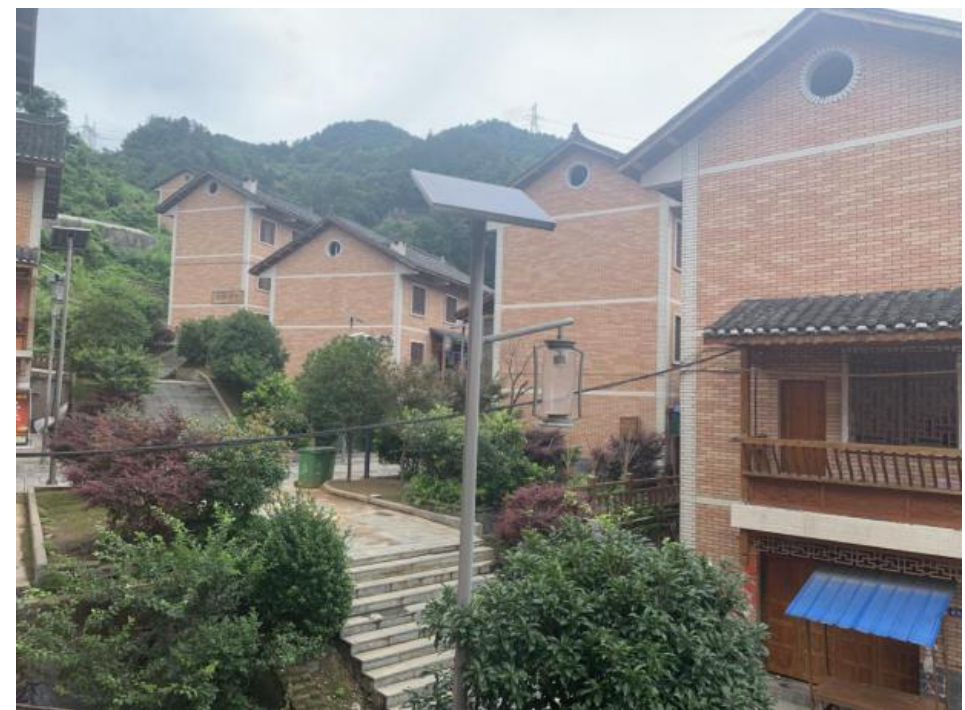

Figure 16. After reconstruction (self-shot by the author).

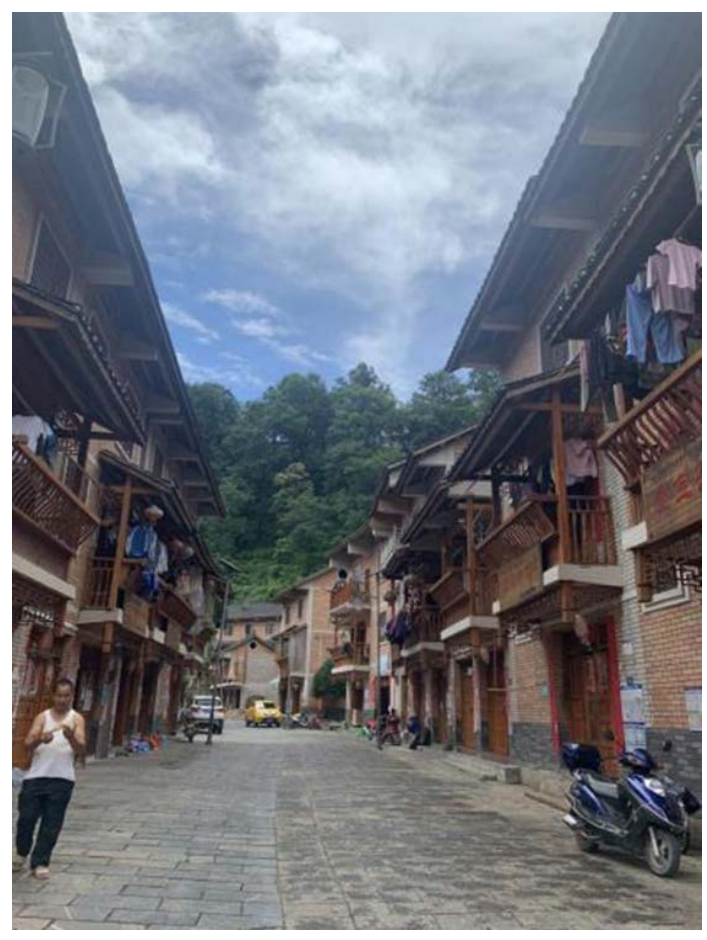

Figure 17. Folk houses.

reconstruction and ecological migration, and a model site for the construction of "Four Rural homes and beautiful villages". In the reconstruction of the building of a strict unified standard, the number of three floors, the total height of no more than 12 meters, the newly built brick and concrete structure of the building to enhance the fire performance, wall bricks, tiles are fire building materials. There were also gaps between the houses and several fire breaks. The livestock enclosure of each household is uniformly set outside the residential area to separate the human and livestock. In addition to the firewalls, villagers in Dongzhai 
in Bajing are organized to conduct a fire drill every month. Fire hydrants are set in the affected areas, and rangers are arranged to inspect the surrounding forest around the clock to avoid fires caused by mountain fires.

In the main road and important nodes installed on the solar lighting system lighting project using antique solar street lights. In Dong Village, two main road loops have been built according to the four-level oil road standard, which can also be used as fire protection passageway when necessary. At the same time, the construction of a number of pedestrian walkways, leisure and tourism trails, as well as access to the line. So that the whole village has formed a traffic network of open-to-traffic, machine-plowing and walking lines, which facilitates the public. It also improves the construction of field leveling, retaining walls, fire protection facilities, three underground (power supply, radio and television, communication network), water supply and drainage system, sewage treatment project, garbage treatment and other sanitation facilities, greening project, street lighting project, public biogas tank and other infrastructure (Figure 18 and Figure 19). Supporting construction at the same time the newspaper Baojing drum tower, embroidery workshop, hit the song hall (LuSheng Chang), sama temple, wash the green pond, catch fish and shrimp, cultural corridor, cultural activity center, sports venues, tourist service center, terminal, parking lot, public toilets, landscape road engineering (including village gate, wind and rain bridge, observatory, the pavilion and road lighting) tourist facilities such as culture, not only meet the basic needs of the Dong village in Baojing people, more satisfied Dong village in Baojing people to beautiful modern life yearning.



Figure 18. Ramp. 




Figure 19. Street lamps (self-photographing).

\subsection{Lifestyle}

The industrious, kind, faithful, honest and diligent people in The Village are the essence of Dong villagers. Most of the villagers who stay in the village keep the traditional way of farming, production and life, which comes from the attachment and worship of nature of Dong Villagers, which is a living embodiment of the traditional culture of Dong Village.

Women in Dong costumes can be seen everywhere through the village, but they are mostly the older generation of women in their 40s. Meanwhile, men rarely wear Dong costumes, only when holding grand activities and celebrations. The traditional costume making technology is still preserved in The Dong Village of Haojing. Dong embroidery, as an intangible cultural heritage, has been completely implanted into the survival and life of dong people. The villagers in Baojing always produce their own clothes for their own use, from the production of cloth to ready-made clothes are finished by their own stitches. During the survey, I was lucky to see an old man weaving cloth on a traditional loom at home, using his hands and feet. Through communication, the old man said that all his clothes came from this loom (Figure 20). When the cloth is finished, it will go through a series of complicated processes such as dyeing, cutting, staining and sewing before it can be finished. Through free interviews and observation during the investigation, it is found that most Villagers of Dong nationality work in the morning by going out to farm. In the afternoon, women can gather in front of a villager's house in pairs according to their distance and distance, sit together and start the embroidery activity of the day, chatting while embroidering (Figure 21). Older men would also gather in groups in groups to sing dong 


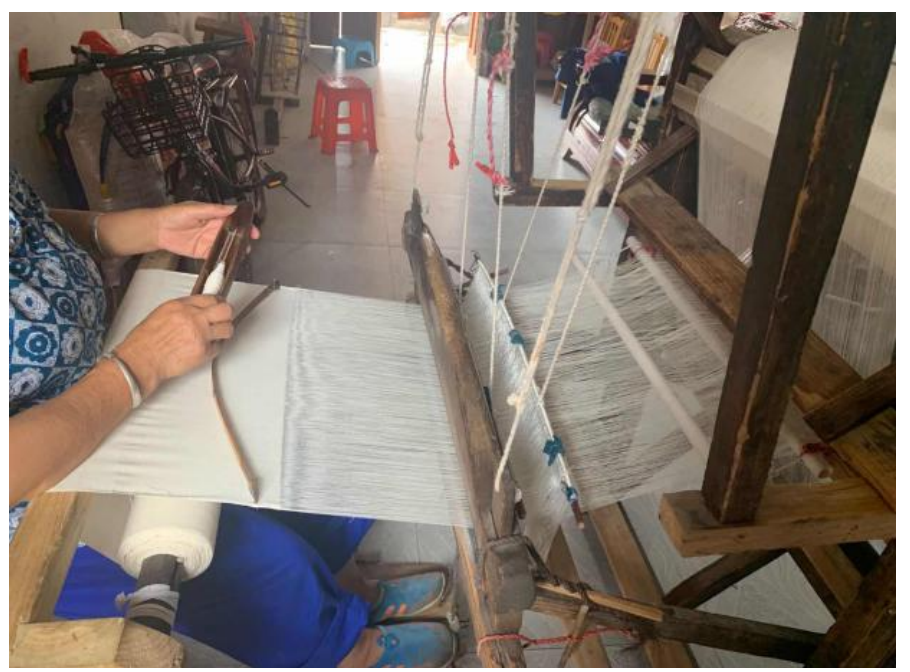

Figure 20. Weaving machine (by the author).

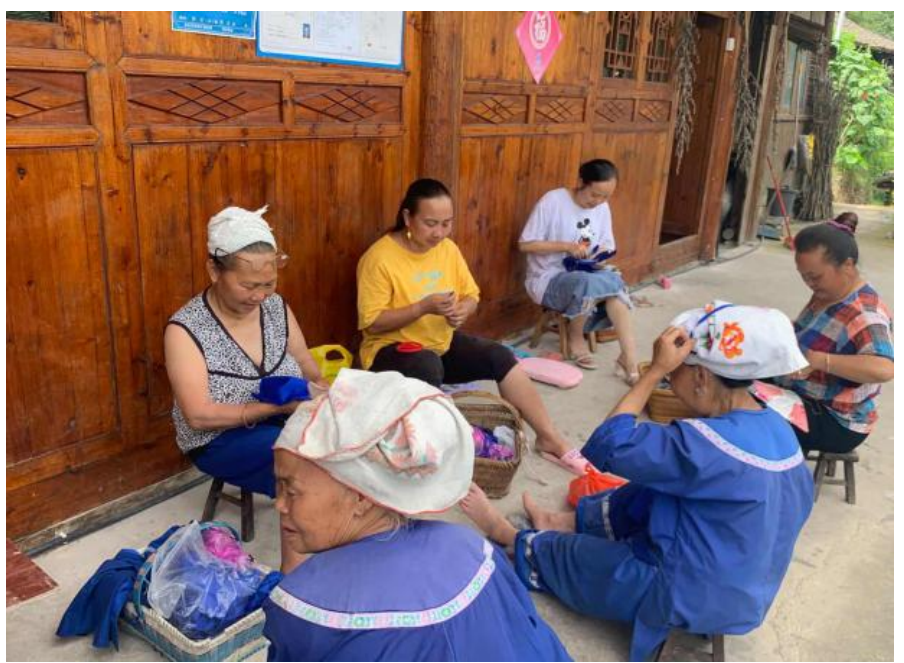

Figure 21. Women embroidery (by the author).

songs and chat. In the leading role of the local government, part of the original work of the young workers return home employment, also in visible to some tourists on both sides of the road and hotels and restaurants as well as the traditional culture characteristics crafts pavilion, such as embroidery, silver shop, etc., the degree of pulling the economic level of the villagers, but also enriched the villagers' way of life.

\section{Thoughts on the Protection and Development of Dong Village in Baijing}

It is difficult to completely avoid the occurrence of disasters, so it is necessary to sort out and study the living environment of the traditional villages rebuilt after the disaster, so as to serve as a warning and reference for other traditional villages. Based on the field investigation of Dong Village in Baijing, the following thoughts and Suggestions are summarized: 


\subsection{Strengthen the Core Value of Village Cultural Sites}

The cultural connotation of traditional villages is carried and embodied through cultural space, and the spirit of place is an indispensable part of the village's living environment. Through field observation and data collection, it is found that the cultural places of Baojing Dong Village have changed to some extent. With the change of life style, more and more young villagers gradually forget the sense of traditional cultural space and place, which makes the frequency of using the cultural places in the village begin to decline and decline. After many years, they even completely forget the significance of the place.

Therefore, in terms of the protection of villages, the propaganda of old and new media of various forms can be utilized to increase the frequency of the use of cultural space and enhance the vitality of cultural sites.

\subsection{Inherit National Beliefs}

National belief is a national historical roots, which includes the view of nature, the universe tube, moral values and beliefs of the architecture space, etc. At present, national culture is in a predicament. With the death of elderly elders, young people gradually lose the edification of traditional culture and become less and less aware of inheriting local culture. For the restoration and inheritance of dong ethnic belief culture in Baojing, the "Kuan system" and "The old village system" of Dong village can be re-restored, and the belief value and inheritance value of dong traditional culture can be popularized to the young generation through the preaching organized by The Village (Lu Jinxia, Chen Xin, 2019) [5].

\subsection{To Reproduce the Traditional Architectural Aesthetics of Villages}

Post-disaster reconstruction Baojing Dong village aims to build ecological emigration demonstration site construction sample point and beautiful countryside, so in the architectural style of the control on the bias of the modern small villa style, the new village of local-style dwelling houses building in colour, style, material and construction volume and the old village dwellings in contrast to a certain degree of damaged Dong village in Baojing overall architectural style, which is unfavorable for the protection and inheritance of traditional architecture. The newly built temples, restored Moga slope, ancient Wells and other cultural places have also been transformed into Chinese style, especially the renovation of the ancient well pavilion, the planting of willow trees and the design of the green stone fence give people a kind of traditional Chinese garden flavor, which completely loses the traditional architectural flavor of Dong Village. During the interview, according to the villagers, before the fire, we could often see the study tour team who went out to paint life in the village, but hardly ever after the reconstruction. Therefore, in the architectural style planning and design stage of traditional villages, the design team should try their best to find a balance between the comfort of buildings and the continuation of traditional features, so as 
to protect the sustainable survival and development of traditional villages.

\subsection{Pay Attention to Protecting the Way of Production and Life of Villages}

While carrying out a large number of poverty alleviation projects to promote economic growth, Dong Village in Baojing also continues the traditional agricultural production mode of Dong Village with diversified production and life styles. The development of traditional villages could not have stalled, the original traditional way of production is not enough to supply the villagers needed for life, in the construction and development in the process of the village, but reasonable optimization of the traditional agricultural production mode, optimize the structure of industry of economy, the introduction of suitable poverty alleviation projects, but should notice to protect arable land, forests, water, vegetation, and living environment of the relationship between the continuation of traditional village buildings spatial scale and layout, make village two levels in the economic and life get sustainable development.

\section{Conclusion}

As a state-level traditional village, this paper analyzes the elements of human settlement environment in the rebuilt of Dong Village in Baojing, summarizes the advantages and disadvantages, and obtains the construction experience, laying a good foundation for the next rational planning of Dong Village according to local conditions.

\section{Conflicts of Interest}

The author declares no conflicts of interest regarding the publication of this paper.

\section{References}

[1] Miao, J.P., Zhang, Y. and Liu, S.H. (2014) Research on the Human Settlement Wisdom of Traditional Settlements: A Case study of Liancun, Fujian Province. Huazhong Architecture, 8, 180-184.

[2] Wei, X.F., Zhao, B.Y. and Wang, Z. (2010) Reconstruction of Lost Space: Exploration on the Protection and Development of Mountain Habitat in the Loose Irrigation Town. Planner, 1, 26-31.

[3] Zhenyuan County Historical Records Office (2009) Zhenyuan, a Famous Historical and Cultural City in China. Writer's Press, Zhenyuan.

[4] Yuan, W.Q. (2018) Research on the Gate Culture of Dong's Village. Jishou University, Jishou.

[5] Lu, J.X. and Chen, X. (2019) Research on the Protection and Development of Traditional Villages from the Perspective of "Cultural Ecology". 2019 China Urban Planning Annual Conference, Chongqing, 19 November 2019, 2395-2411. 